\title{
Sustainable Luxury: The Effect of Luxury Consumption Motivations on Corporate Social Responsibility Strategies: An Abstract
}

\author{
Carmela Donato, Matteo De Angelis, and Cesare Amatulli
}

\begin{abstract}
Luxury industry and corporate social responsibility (CSR) activates are generally considered as incompatible concepts by consumers. This is because luxury is generally related to hedonism, excess, and ostentation, while CSR is generally based on sobriety, moderation, and ethics. However, nowadays more and more luxury companies seem highly committed toward sustainability. For example, Tiffany started certifying its diamonds as "conflict-free," Chanel incorporated "earthy materials" in its 2016 collection, and Bulgari has recently funded restoration of Rome's Spanish Steps. Therefore, it seems plausible the presence of a certain compatibility degree between luxury and CSR activities. However, this issue has received very limited empirical investigation from marketing literature. As a consequence, the present research aims to empirically test whether and under what conditions consumers react to different kinds of luxury companies' CSR initiatives. Using Carroll's four-dimension model of internal vs. external CSR, we argue and demonstrated that luxury companies' internal (versus external) CSR initiatives increase willingness to buy luxury products, but mainly for those customers who buy luxury for internal motivations and not for status ostentation, as, for example, individual style and personal taste.
\end{abstract}

References Available Upon Request

\author{
C. Donato $(\varangle) \cdot$ M. De Angelis \\ Luiss University, Rome, Italy \\ e-mail: donatoc@luiss.it; mdeangelis@luiss.it \\ C. Amatulli \\ University of Bari, Bari, Italy \\ e-mail: cesare.amatulli@uniba.it
}

